\title{
427 エレベータ巻上機のトルク制御によるかご上下振動の低減
}

\author{
Vertical Vibration Suppression of Elevator by Torque Control of Traction Machine \\ ○川 雄一郎 (東京農工大学大学院) \\ 正 鎌田 崇義 \\ (東京農工大学大学院) \\ 正 永井 正夫（東京農工大学大学院） \\ 正 松岡 寛晃（東芝エレベータ）
}

Yuichiro OKAWA, Tokyo University of Agri. and Tech. , 2-24-16, Nakacho, Koganei-shi, Tokyo Takayoshi KAMADA, Tokyo University of Agri. and Tech.

Masao NAGAI, Tokyo University of Agri. and Tech.

Hiroaki MATSUOKA, Toshiba Elevator and Building Systems Corporation

\begin{abstract}
Recently, riding quality becomes an important item for elevator system. Many studies on vibration suppression of elevator have been conducted. In this paper, vertical vibration suppression by controlling the torque of the elevator traction machine motor is discussed. Additionally, the effects of the switching of linear controllers designed by H-infinity control theory according to the position of the elevator are also examined because the transfer characteristic from motor torque to car acceleration depends on the rope length from the car to the main sheave. The simulation result shows that the car vertical vibration is efficiently suppressed by adopting this method.
\end{abstract}

Keywords: Elevator, Vertical Vibration Suppression, H-infinity Control, Controller Switching

\section{A1. 緒言}

エレベータにおいて乗りかごの振動を抑えることは品 领・性能の点から重要な課題であり, 乗りかごの振動を低 減する方法についての研究が行われてきた。 中でも乗りか ごの上下振動は，乗り心地を悪化させる要因の一つである とされている[1]が，近年のエレベータはロープ径が縮小化 されており，ロープの伸び縮みによって上下振動が発生し やすくなっている．特に人が不快と感じやすい周波数帯に おいて,この上下振動を抑制することは重要な課題である.

本研究では巻上機のトルクを制御することにより，乗り かご上下振動を低減することを目的とする．また，エレべ 一タの巻上機トルクに起因する乗りかご上下振動の伝達特 性は，かごの位置によって大きく変化することから，一っ の線形制御器で振動を抑制することが難しい，そこで三つ の線形制御器を設計し, かご位置に応じて制御器を切り替 えていく制御手法を提案する。本報告では設計した制御系 の有効性をシミュレーションにより確認した.

$$
\text { A2. シミュレーションモデル }
$$

図 A1 に本研究で対象とするエレベータモデルを示す. 最大積載量 $600 \mathrm{~kg}$ で, 停止階は一階から五階までとなって いる.

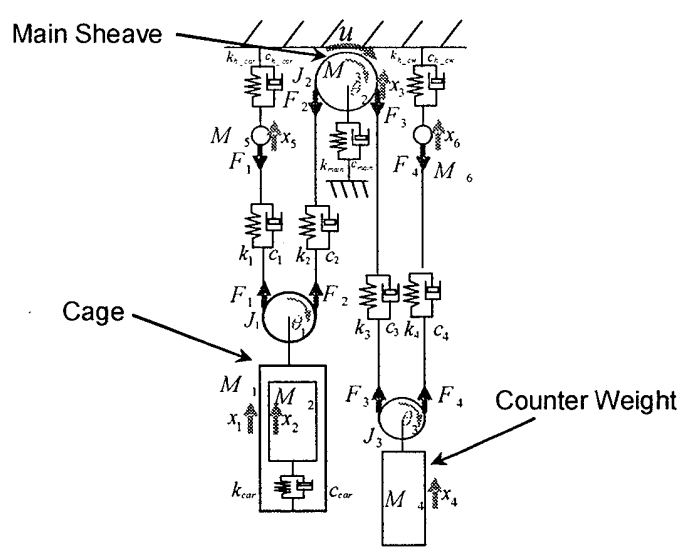

Fig.Al Simulation model of elevator

\section{A3. 制御系設計}

今回，振動低減の対象とするのは一次モードである約 $5 \mathrm{~Hz}$ のロープの弾性振動であり，その周波数帯域において 振動を抑えるよう制御器を設計した.制御器は $\mathrm{H}_{\infty}$ 制御理論 を用いて設計を行った。また, 最上階, 中間階, 最下階に おいてそれぞれ設計を行い, 三つの制御器を位置に応じて 切り替える制御系を構築した。

A4. シミュレーション結果

設計した三つの制御器を用い，走行シミュレーションを 行った. 外乱としてかご枠に振幅 $10 \mathrm{~N}$, 周波数 $5.3 \mathrm{~Hz}$ の正 弦波外乱を与えた際のかご室加速度の結果を図 $\mathrm{A} 2$ に示す.

走行条件は開始 $2.65 \mathrm{~s}$ 加方向に加速し，一定速度で 4.7 秒間等速運動させた. その後 $9.85 \mathrm{~s}$ から減速し, 15 秒間 で最上階から最下階へ移動するようにした。制御器は，0 〜 7.5s 最上階制御器, 7.5 9.5s を中閒階制御器, 9.5 15s を最下階制御器とし, 切り替え時にショックが入らないよ う0.5 秒間かけて滑らかに切り替えている.

図 A2 の結果を見ると, 外乱を入力した走行シミュレー ションにおいて, 制御器を用いることで振動低減効果が確 認できた，今後は実際のエレベータに実装することで，制 振効果を確認する予定である。

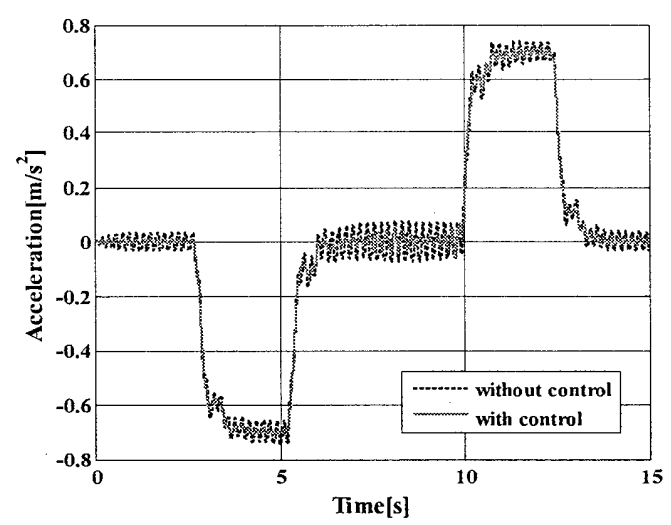

Fig.A2 Time histories of car acceleration 


\section{1. 緒言}

エレベータにおいて乗りかごの振動を抑えることは品 質・性能の点から重要な課題であり, 乗りかごの振動を低 減する方法について多数の研究が行われてきた，中でも乗 りかごの上下振動は, 乗り心地を悪化させる要因の一つで あるとされている[1]. 近年のエレベータはロープ径が縮小 化されており，ロープの伸び縮みによって上下振動が発生 しやすくなっており，特に人が不快と感じやすい周波数帯 において，乗りかごの上下振動を抑制することは重要な課 題である.

本研究では巻上機のトルクを制御することにより，乗り かご上下振動を低滅することを目的とする. また，エレべ 一タの巻上機トルクに起因する乗りかご上下振動の伝達特 性は，かごの位置によって大きく変化することから，一っ の線形制御器で振動を抑制することが難しい，そこで三つ の線形制御器を設計し, かご位置に応じて制御器を切り替 えていく制御系を提案する。本報告では設計した制御系の 有効性をシミュレーションにより確認した.

$$
\text { 2. シミュレーションモデル }
$$

図 1 に本研究で対象とするエレベータのモデルを示す. 最大積載量 $600 \mathrm{~kg}$ で，一階から五階まで移動可能な標準型 エレベータである. エレベータは上部の巻上機からロープ で支持されており,釣合い錘であるカウンターウェイト（以 下 $\mathrm{CW}$ )によって重量バランスを取りながら走行を行う。 上下方向, 回転方向, ロープ力の各運動方程式を式 (1) 式（3）に示す.

ここで, $M_{1}$ : かご枠重量, $M_{2}$ : かご室重量, $M_{3}$ : 巻上機 重量, $M_{4}: \mathrm{CW}$ 重量, $M_{5}, M_{6}:$ ダミーマス, $J_{1}:$ かご上滑車 慣性モーメント, $J_{2}$ : 巻上機慣性モーメント, $J_{3}: \mathrm{CW}$ 上滑 車慣性モーメント， $r_{1}$ : かご上滑車半径, $r_{2}$ : 巻上機半 径, $r_{3}: \mathrm{CW}$ 上滑車半径, $k_{h_{-} \text {car }}$ :かご上ヒッチばね定 数, $k_{h_{-} w}: \mathrm{CW}$ 上ヒッチばね定数, $k_{c a r}:$ かご防振ゴムばね定 数, $k_{\text {main }}$ : 巻上機防振ゴムばね定数, $c_{h_{-} \text {car }}$ :かご上ヒッチ減衰 係数, $c_{h_{-}-w}: \mathrm{CW}$ 上ヒッチ減衰係数, $c_{c a r}$ : かご防振ゴム減衰係 数, $c_{\text {main }}$ :巻上機防振ゴムば视定数, $k_{1}, k_{2}, k_{3}, k_{4}$ :ロープ の単位長さあたりのばね定数, $c_{1}, c_{2}, c_{3}, c_{4}$ : ロープの単 位長さあたりの減衰係数, $u$ :入力トルクとする.

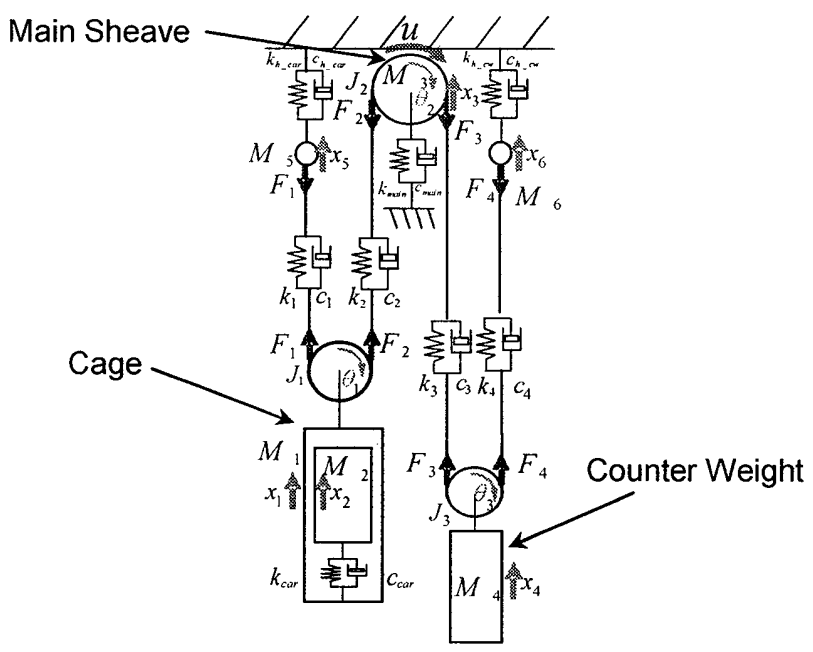

Fig.1 Simulation model of elevator

$$
\begin{aligned}
& \left\{\begin{array}{l}
M_{1} \ddot{x}_{1}=F_{1}+F_{2}+F_{c a g e}-k_{c a r}\left(x_{1}-x_{2}\right)-c_{c a r}\left(\dot{x}_{1}-\dot{x}_{2}\right) \\
M_{2} \ddot{x}_{2}=F_{c a r}+k_{c a r}\left(x_{1}-x_{2}\right)+c_{c a r}\left(\dot{x}_{1}-\dot{x}_{2}\right) \\
M_{3} \ddot{x}_{3}=-F_{2}-F_{3}-k_{\text {main }} x_{3}-c_{\text {main }} \dot{x}_{3} \\
M_{4} \ddot{x}_{4}=F_{3}+F_{4}+F_{c o w} \\
M_{5} \ddot{x}_{5}=-F_{1}-k_{h_{-} c a r} x_{5}-c_{h_{-} c a r} \dot{x}_{5} \\
M_{5} \ddot{x}_{6}=-F_{4}-k_{h_{-} c w} x_{6}-c_{h_{-} c w} \dot{x}_{6}
\end{array}\right. \\
& \left\{\begin{array}{l}
J_{1} \ddot{\theta}_{1}=F_{1} r_{1}-F_{2} r_{1} \\
J_{2} \ddot{\theta}_{2}=F_{3} r_{2}-F_{2} r_{2}+u \\
J_{3} \ddot{\theta}_{3}=F_{3} r_{3}-F_{4} r_{3}
\end{array}\right. \\
& \left\{\begin{array}{l}
F_{1}=k_{1}\left(x_{5}-x_{1}-r_{1} \theta_{1}\right)+c_{1}\left(\dot{x}_{5}-\dot{x}_{1}-r_{1} \dot{\theta}_{1}\right) \\
F_{2}=k_{2}\left(x_{3}-x_{1}+r_{2} \theta_{2}+r_{1} \theta_{1}\right)+c_{2}\left(\dot{x}_{3}-\dot{x}_{1}+r_{2} \dot{\theta}_{2}+r_{1} \dot{\theta}_{1}\right) \\
F_{3}=k_{3}\left(-x_{4}-r_{2} \theta_{2}-r_{3} \theta_{3}\right)+c_{3}\left(-\dot{x}_{4}-r_{2} \dot{\theta}_{2}-r_{3} \dot{\theta}_{3}\right) \\
F_{4}=k_{4}\left(x_{6}-x_{4}+r_{3} \theta_{3}\right)+c_{4}\left(\dot{x}_{6}-\dot{x}_{4}+r_{3} \dot{\theta}_{3}\right)
\end{array}\right.
\end{aligned}
$$

\section{3. 制御系設計}

\section{1 モデルの同定}

実験によりモデルのパラメータ同定を行った．実験条件 は乗りかごを最上階, 中間階, 最下階それぞれの位置にお いて, 巻上機トルクに振幅 $10 \mathrm{Nm}, 0.5 \sim 30 \mathrm{~Hz}$ の sweep 波を 入力した. その際のかご室, かご枠, $\mathrm{CW}$ の加速度を測定 し, 巻上機トルクから各加速度までの周波数応答を求め, シミュレーション結果と比較した. 最上階および中間階で の巻上機トルクに対するかご室加速度までの周波数応答を それぞれ図2、図 3 に示寸.

図 2, 図 3 の結果から，5Hz 及び $12 \mathrm{~Hz}$ でのゲインピーク を一致させることができていることがわかる.ここで, $5 \mathrm{~Hz}$ はロープ弾性一次振動であり, $12 \mathrm{~Hz}$ はかご室とかご枠の逆 位相振動であることも確認できた. また, 中閒階では $5 \mathrm{~Hz}$ のゲインピークが小さく，トルクを入力しても制御効果が 得られにくいことが分かった，さらに，トルク入力に対す る応答加速度が最下階においては最上階と位相が反転する ことが確認されており，一つの制御器では制振効果が得ら れないため, 最上階, 中間階, 最下階においてそれぞれ制 御器を設計する.さらに今回対象としているのはロープの 弾性一次振動であり, 対応する固有振動数である $5 \mathrm{~Hz}$ 近傍 でのゲインを下げるように制御器の設計を行う.
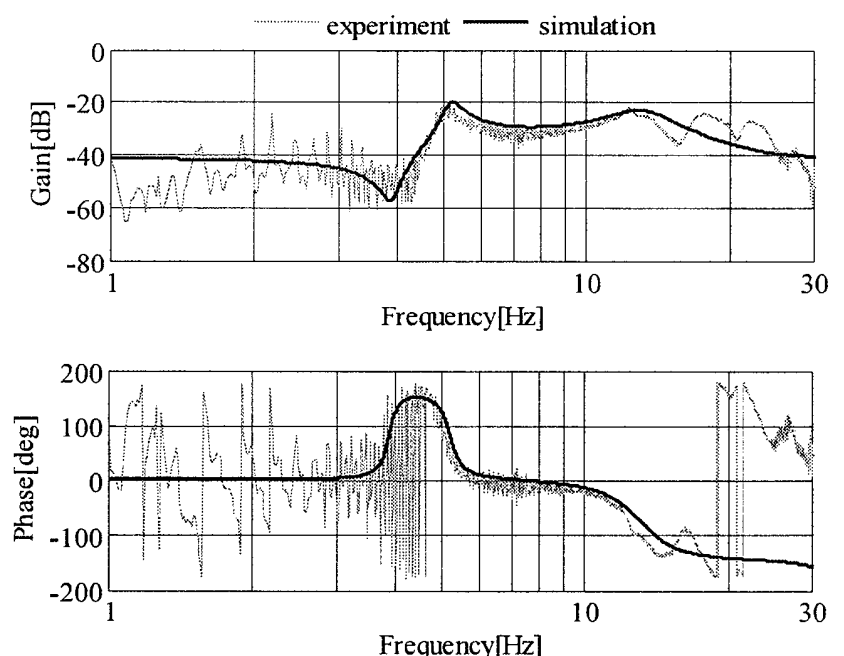

Fig.2 Frequency response in the highest floor 

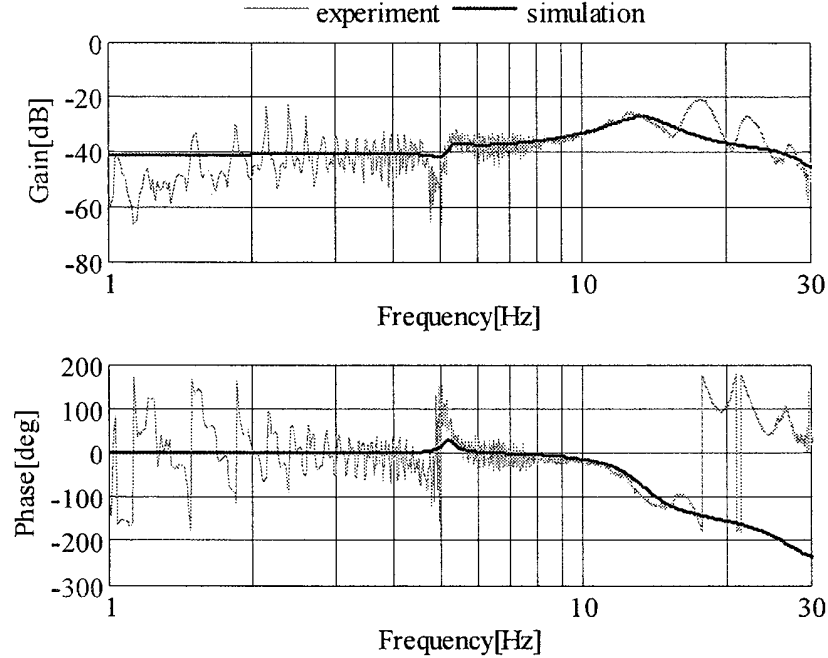

Fig.3 Frequency response in the middle floor

\section{2 制御器設計 ${ }^{[2]}$}

前述したように，本研究では最上階，中間階，最下階に おいてそれぞれ制御器を設計し，三つの制御器を切り替え る制御系を提案する. 本研究では，制御対象 $P$ の入力側に かご枠外乱 $d$, 出力側に仮想外乱 $w$ を想定した修正混合感 度問題を適用し $\mathrm{H}_{\infty}$ 制御器を設計した.一般化プラントのブ ロック線図を図 4 に示す。ここで， $P$ : プラント， $K$ : 制 御器, $W_{s}$ : 外乱抑圧に関する重み関数, $W_{1}$ : 加法的誤差に 対する重み関数, $W_{n}$ : 乗法的誤差に関する重み関数, $Z_{1}$, $Z_{2}$ : 制御量, $y$ : フィードバック信号(かご室加速度), $u$ : 制 御入力(巻上げトルク)を表している. 図 4 で示した一般化 プラントに対して，以下の重み関数を設定する．重み関数 を式(4)〜式(6)に示す. 最上階における制御器の各式中のパ ラメータを表 1 に, 重み関数の周波数応答を図 5 に示す. 残りの 2 つ制御器も同じ形の関数を用いて設計した.

$$
\begin{aligned}
& W_{s}(s)=k_{s} \cdot \frac{s^{2}+2 \pi \omega_{s} s+\omega_{s}^{2}}{s^{2}+\pi \zeta_{s} \omega_{s} s+\omega_{s}^{2}} \\
& W_{t}(s)=k_{t} \cdot \frac{s^{2}+\pi \zeta_{t} \omega_{t} s+\omega_{t}^{2}}{s^{2}+2 \pi \omega_{t} s+\omega_{t}^{2}} \\
& W_{n}(s)=k_{n}
\end{aligned}
$$

$W_{s}$ は，ロープの弾性一次振動である $5 \mathrm{~Hz}$ 付近で大きなゲ インをもつような重み関数に設定した。 $W_{t}$ はロバスト性を 考慮し, 制御帯域以外の周波数帯域で大きなゲインを持た せた. $W_{n}$ は制御器の次数を上げないよう, 微小な定数とし た。また，振動制御のための巻上機トルクは，エレベータ の通常走行に影響を与えないよう上限をモ一タの定格卜ル クの $10 \%$ 以内として設計を行った。

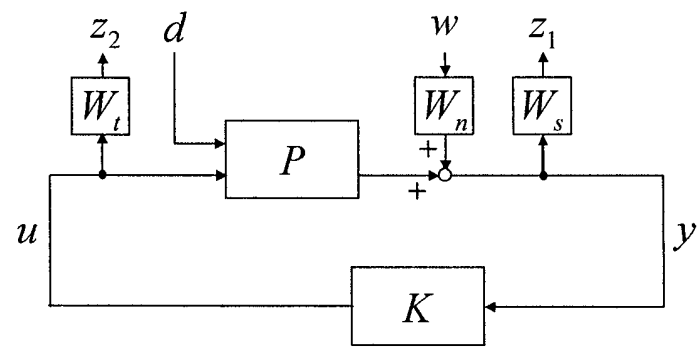

Fig.4 Generalized plant for $\mathrm{H}_{\infty}$ controller
Table 1 Parameters of weighting function

\begin{tabular}{|c|c|c|}
\hline \multicolumn{2}{|c|}{ Symbol } & Value \\
\hline \multirow{3}{*}{$W_{s}$} & $\omega_{s}$ & $2 \cdot \pi \cdot(5.3)$ \\
\cline { 2 - 3 } & $\zeta_{s}$ & 0.05 \\
\cline { 2 - 3 } & $k_{s}$ & 0.04 \\
\hline \multirow{3}{*}{$W_{t}$} & $\omega_{t}$ & $2 \cdot \pi \cdot(5.3)$ \\
\cline { 2 - 3 } & $\zeta_{t}$ & 0.1 \\
\cline { 2 - 3 } & $k_{t}$ & 0.07 \\
\hline$W_{n}$ & $k_{n}$ & 0.001 \\
\hline
\end{tabular}

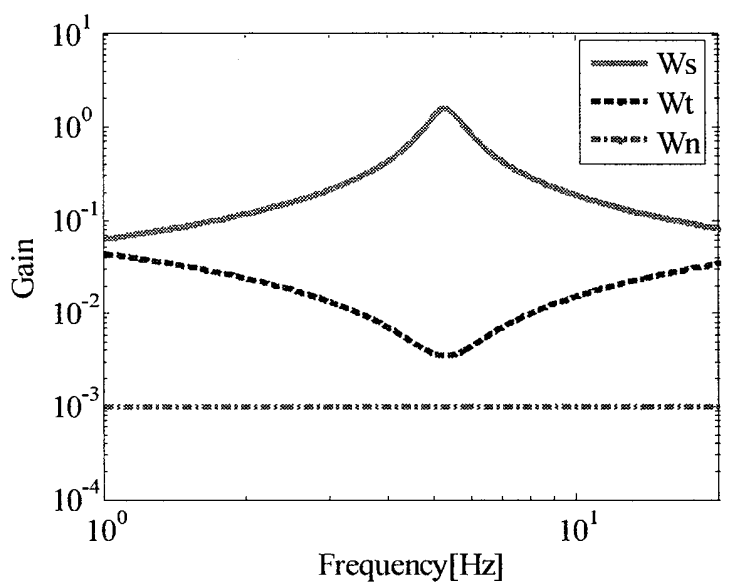

Fig.5 Weighting function

4. シミュレーション結果

4.1 乗りかご固定でのシミュレーション

乗りかごを最上階, 中間階, 最下階の位置に固定し，か ご枠に加えた外乱に対するかご室加速度までの周波数応答 を求めた。最上階での制御なし及び, 制御器を用いた際の 結果を図 6 に示す. また，かご枠に振幅 $10 \mathrm{~N}$, 周波数 $5.3 \mathrm{~Hz}$ の正弦波外乱を与えた際のかご室加速度及び，制御トルク の時系列応答を図 7 に示す.グラフから制御器を用いるこ とにより，5Hz 近傍のゲインピークがさがり，正弦波外乱 を入力しても十分振動が低減していることが確認できた。 また, 制御トルクも $0.6 \mathrm{Nm}$ 程度であり, 巻上機モータが出 力可能な範囲内にある.

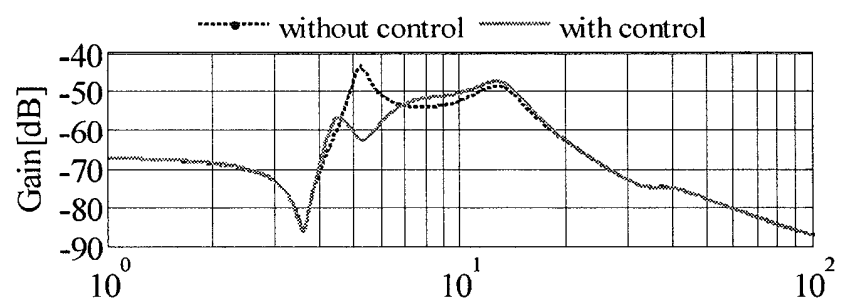

Frequency[Hz]

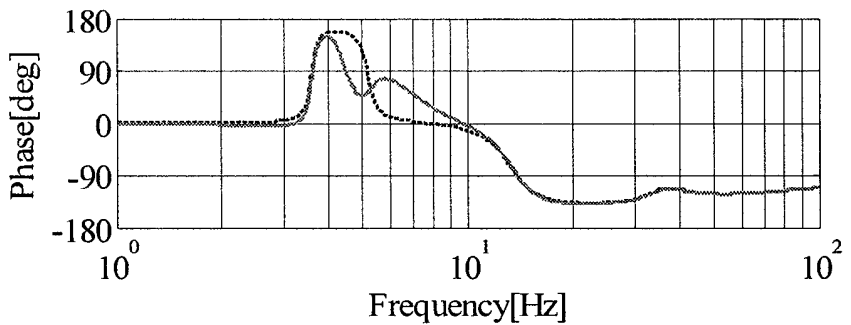

Fig.6 Frequency response in the highest floor 

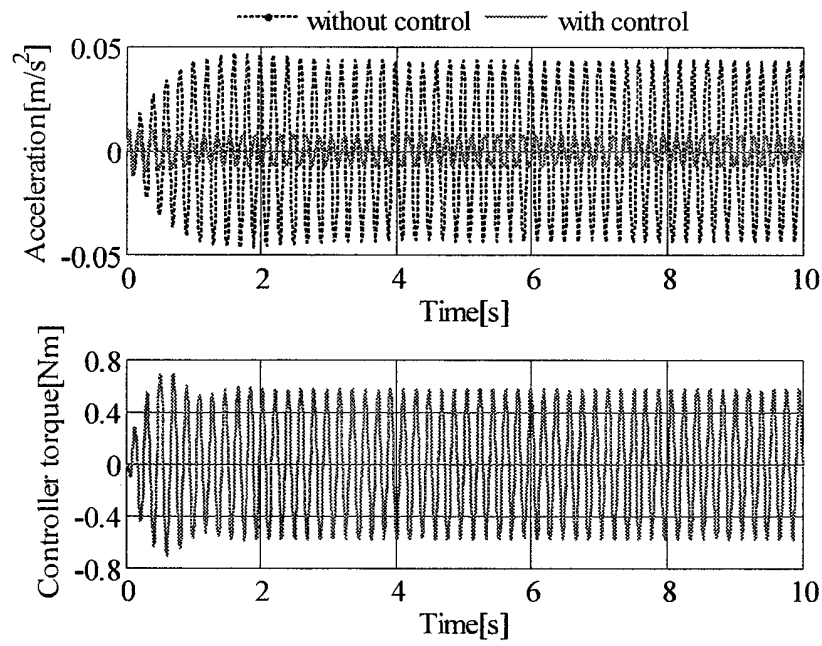

Fig. 7 Car acceleration and control torque against sinusoidal disturbance

4.2 走行シミュレーション

走行シミュレーションのブロック線図を図 8 に示す。走 行に要する巻上機トルクと, 振動低減に要する制御トルク を足し合わせたものを指令トルクとしてモデルに入力する. 走行条件は開始 $2.65 \mathrm{~s}$ 加方方向に加速し, 一定速度で 4.7 秒閒等速運動させた。 その後 $9.85 \mathrm{~s}$ から減速を開始し， 15 秒間で最上階から最下階へ移動するようにした。このとき のかご室の上下方向の変位を図 9 に示す.

制御器は, $0 \sim 7.5 \mathrm{~s}$ を最上階制御器, 7.5 9.5s を中間階 制御器, 9.5 15s を最下階制御器とし, 切り替えの際にシ ヨックが入らないよう 0.5 秒間かけて滑らかに切り替えを 行っている.

外乱としてかご枠に振幅 $10 \mathrm{~N}$, 周波数 $5.3 \mathrm{~Hz}$ の正弦波外 乱を与えた際のかご室加速度の結果を図 10 に示す.制御を 付加することで振動低減効果が確認できた。また制御トル クも図 11 に示すように $10 \mathrm{Nm}$ 以内であり, 巻上機トルクの 制限内であることが確認できた，切り替え時にも大きな衝 揧は入っておらず, 滑らかな切り替えが実現できた。

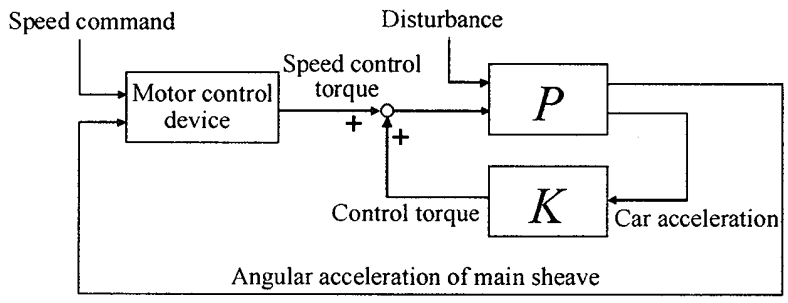

Fig.8 Block diagram of control system

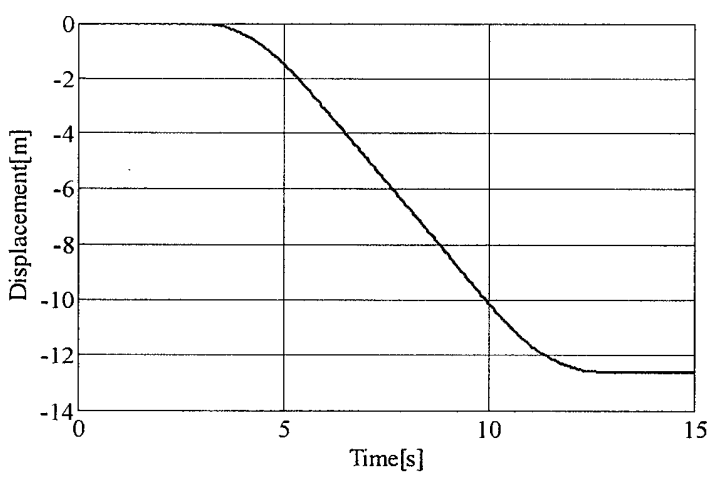

Fig.9 Vertical displacement

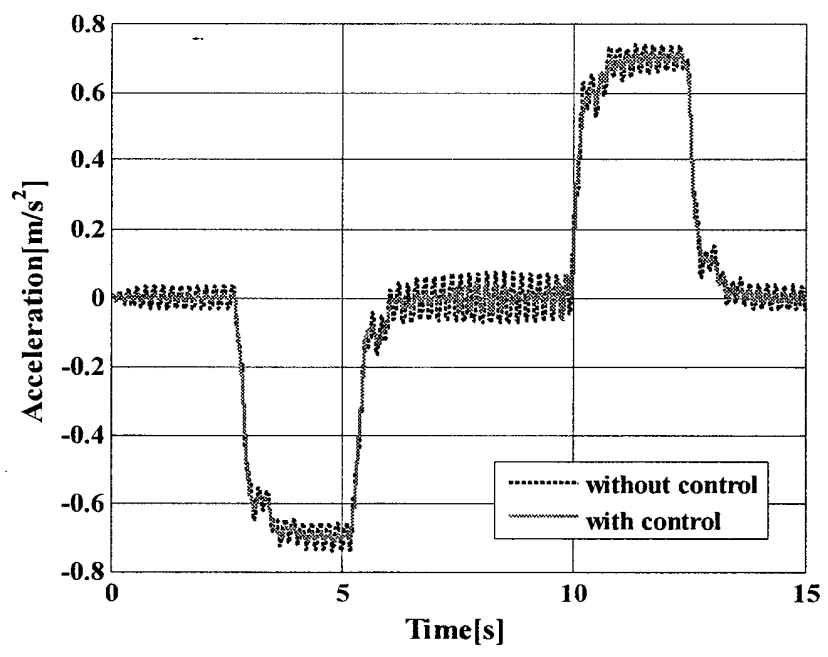

Fig.10 Vertical acceleration of elevator car

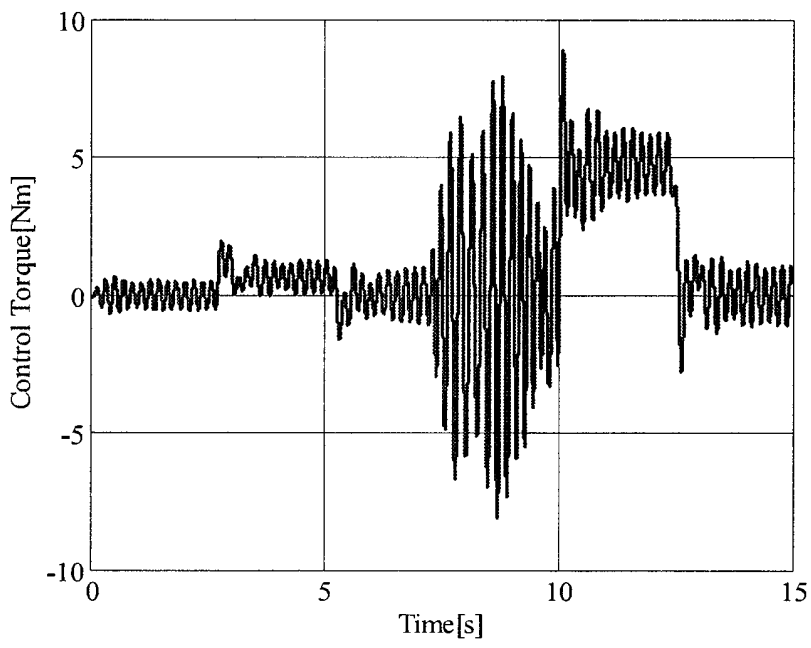

Fig.11 Control torque

6. 結言

1）同定実験から作成したモデルが実機と一致することが 確認できた。

2) 乗りかごを最上階, 中間階, 最下階の位置に固定し, それぞれにおいて $\mathrm{H}_{\infty}$ 制御器を設計することで, 制振 効果を確認した.

3）走行シミュレーションにおいて三つの制御器を切り替 えることで，走行中においても制振効果を確認寸るこ とができた。

4) 制御器切り替えの際に, 各制御力に重みをかけ，それ らを足し合わせることによって滑らかな切り替えを行 うことができた。

今後、実機を用いた制御実験を行って提案した手法の妥当 性を実験的にも確認する予定である。

\section{参考文献}

[1] 荒川淳ほか, エレベータかご振動抑制制御, Dynamics and Design Conference 2002 CD-ROM 論文集

[2] 野波健蔵, 西村秀和, 平田光男：MATLABによる制御 系設計，東京電機大学出版局，(1998)，103-139. 